\title{
PEMBERDAYAAN EKONOMI MASYARAKAT BERBASIS EKONOMI KREATIF DI DESA CITAMAN KECAMATAN CIOMAS KABUPATEN SERANG BANTEN
}

\author{
${ }^{1)}$ AR Chaerudin, ${ }^{2)}$ Bambang Setiadi, ${ }^{3)}$ Ahmad Munawir \\ Fakultas Ekonomi dan Bisnis, Fakultas Ilmu Komputer, Universitas Bina Bangsa \\ ${ }^{1)}$ Email : abdulrauf.Chaerudin@binabangsa.ac.id \\ ${ }^{2)}$ Email : bambang.setiadi@binabangsa.ac.id \\ ${ }^{2)}$ Email : ahmad.munawir@binabangsa.ac.id
}

\begin{abstract}
ABSTRAK
Pergeseran orientasi ekonomi dunia yang mengedepankan aset sumber daya manusia ini menyebabkan persaingan luar biasa dalam dunia kreatif (global competition of talents). Pembangunan pedesaan melalui industrialisasi pertanian atau peningkatan produksi pangan berbasikan penegembangan wilayah serta berbasiskan pertumbuhan ekonomi. Desa Citaman Kecamatan Ciomas Kabupaten Serang Provinsi Banten Wilayah Desa Citaman adalah desa yang berbasis pertanian dan perkebunan, dan beberapa potensi ada Usaha Mikro dan Kecil diantaranya Emping, Tempe, dan Kerupuk. Dan saat ini di desa tersebut sangat diperlukan adanya pengembangan-pengembangan usaha yang tepat guna. Pelaksanaan pendampingan dan pengembangan masyarakat merupakan salah satu tujuan dari kegiatan PPM yang diharapkan mampu untuk dapat menyelesaikan permasalahan yang ada di masyarakat Desa Citaman, baik di bidang perekonomian, keagamaan, sosial dan budaya, pemerintahan desa, maupun di bidang pendidikan dan kesehatan. Melalui pendampingan terhadap masyarakat, kegiatan PPM Dosen ini melakukan penggalian data tentang persoalan atau kondisi masyarakat sekitar yang selanjutnya dirumuskan dalam bentuk program kerja dan realisasinya yang diharapkan dapat menjawab persoalan yang ada bersama dengan masyarakat. Kemudian program kerja yang dirumuskan telah terealisasi kurang lebih $90 \%$ sesuai dengan kemampuan peserta PPM, meskipun masih terdapat kendala dalam pelaksanaannya.
\end{abstract}

Kata Kunci : Pemberdayaan Ekonomi, Ekonomi Kreatif 


\section{PENDAHULUAN}

Arus globalisasi dan liberalisasi ekonomi dunia bergerak begitu cepat mendorong semakin meningkatnya keterbukaan hubungan ekonomi antar-bangsa dan mendorong persaingan yang semakin meningkat. Menurut Forum Ekonomi Dunia (World Economic Forum) tentang daya saing global, Indonesia dalam Laporan Indeks Daya Saing WEF 20162017, posisi Indonesia tidak lebih baik dibandingkan dengan negara tetangganya di Asia Tenggara, seperti Thailand (34), Malaysia (25), dan Singapura (2). Namun, Indonesia masih unggul dibandingkan dengan Filipina (57), Vietnam (60), dan Laos (93). Meski skornya tetap $(4,52)$, posisi Indonesia melorot empat level setelah disalip sejumlah negara. Daya saing Indonesia 2016-2017 berada di peringkat 41 atau turun empat peringkat dibanding posisi tahun lalu yang berada di urutan 37. Seperti dimuat dalam Global Competitiveness Index, meski Indonesia telah banyak melakukan reformasi di berbagai sektor, namun secara performance empat negara lain berhasil menggeser posisi Indonesia. Negara tersebut yakni Malta, India, Kuwait dan Azerbaijan. Pergeseran orientasi ekonomi dunia yang mengedepankan aset sumber daya manusia ini menyebabkan persaingan luar biasa dalam dunia kreatif (global competition of talents). Pembangunan pedesaan melalui industrialisasi pertanian atau peningkatan produksi pangan berbasikan penegembangan wilayah serta berbasiskan pertumbuhan ekonomi serta pendekatan pembangunan pedesaan yang berbasis pada ekonomi dan sosial kreatif ini perlu dipahami bagaimana kekuatannya untuk menggerakkan perekonomian desa (Kusuma, Jaka Wijaya; Jefri, Ulfi; Surnani, Endang; Pratiwi, Ika; Kurniawan, 2020).

\section{Sejarah Singkat Desa Citaman}

Sebelum tahun 1982 Desa Citaman Kecamatan Ciomas Kabupaten Serang, masih masuk ke dalam desa induk, yaitu Desa Pondok Kahuru. Pada tahun 1982 Desa Pondok Kahuru dimekarkan menjadi dua desa, yaitu Desa Pondok Kahuru dan Desa Citaman, yang masig-masing dipimpim oleh dua orang Kepala Desa sebagai berikut :

1. Desa Pondok Kahuru dipimpin oleh Baesuni.

2. Desa Citaman dipimpin oleh Sokari (PJS). 


\section{Letak Geografis Desa Citaman}

1. Batas Wilayah

Secara geografis, Desa Citaman berbatasan dengan :

- Sebelah Utara : Desa Pondok Kahuru

- Sebelah Selatan : Gunung Karang

- Sebelah Timur : Desa Panyaungan Jaya

- Sebelah Barat : Desa Lebak

2. Orbitasi (Jarak dari Pusat Pemerintahan)
a. Jarak dari pusat pemerintahan Kecamatan
$: 2 \mathrm{Km}$
b. Jarak dari Ibukota Kabupaten Serang
$: 21 \mathrm{Km}$
c. Jarak dari Ibukota Provinsi Banten
: $17 \mathrm{Km}$
Jarak dari Ibukota Negara
: $102 \mathrm{Km}$

\section{Tabel 2}

Orbitasi (Jarak Antar Ibukota)

\begin{tabular}{|c|c|c|c|c|c|}
\hline Jarak (KM) & $\begin{array}{c}\text { Desa } \\
\text { Citaman }\end{array}$ & $\begin{array}{c}\text { Ibukota } \\
\text { Kecamatan }\end{array}$ & $\begin{array}{c}\text { Ibukota } \\
\text { Kabupaten }\end{array}$ & $\begin{array}{c}\text { Ibukota } \\
\text { Provinsi }\end{array}$ & $\begin{array}{c}\text { Ibukota } \\
\text { Negara }\end{array}$ \\
\hline $\begin{array}{c}\text { Desa Citaman } \\
\text { Ibukota } \\
\text { Kecamatan }\end{array}$ & 0 & 2 & 21 & 17 & 102 \\
\hline $\begin{array}{c}\text { Ibukota } \\
\text { Kabupaten }\end{array}$ & 21 & 19 & 0 & 4 & 85 \\
\hline $\begin{array}{c}\text { Ibukota } \\
\text { Provinsi }\end{array}$ & 17 & 15 & 4 & 0 & 81 \\
\hline $\begin{array}{c}\text { Ibukota } \\
\text { Negara }\end{array}$ & 102 & 100 & 85 & 81 & 0 \\
\hline
\end{tabular}

3. Luas Wilayah

Luas wilayah Desa Citaman adalah $506 \mathrm{Ha}$, dengan penggunaannya sebagai 
berikut:
a. Pemukiman : $35 \mathrm{Ha}$
b. Perkantoran : $6 \mathrm{Ha}$
c. Pertanian : $2 \mathrm{Ha}$
d. Perkebunan : $253 \mathrm{Ha}$
e. Peternakan : $1 \mathrm{Ha}$
f. Perikanan : $1 \mathrm{Ha}$
g. Fasilitas Umum : $5 \mathrm{Ha}$
h. Fasilitas Sosial : $3 \mathrm{Ha}$
i. Hutan : $200 \mathrm{Ha}$

\section{Topografi Desa}

Secara umum keadaan Desa Citaman merupakan daerah dataran tinggi dengan ketinggian 800 meter di atas permukaan laut. Desa Citaman mempunyai iklim tropis sehingga mempunyai pengaruh langsung terhadap aktivitas pertanian dan pola tanam di desa ini.

\section{Keadaan Demografis Desa}

1. Kependudukan

Jumlah penduduk Desa Citaman sebanyak 2.949 jiwa dengan jumlah Kepala Keluarga sebanyak 639 Kepala Keluarga. Penanganan kependudukan sangat penting sehingga potensi yang dimiliki mampu menjadi pendorong dalam pembangunan, khususnya pembangunan Desa Citaman. Berkaitan dengan kependudukan, aspek yang penting antara lain perkembangan jumlah penduduk, kepadatan, dan persebaran serta strukturnya.

\section{Tabel 3}

\section{Jumlah Penduduk Berdasarkan Jenis Kelamin}

\begin{tabular}{|c|c|c|}
\hline No. & Jenis Kelamin & Jumlah Jiwa \\
\hline 1. & Laki-laki & 1.496 \\
\hline 2. & Perempuan & 1.453 \\
\hline
\end{tabular}




\section{Total}

2.949

2. Pertumbuhan Jumlah Penduduk

Jumlah penduduk Desa Citaman cenderung meningkat karena tingkat kelahiran lebih besar daripada tingkat kematian serta penduduk yang masuk lebih besar dari penduduk yang keluar. Laju pertumbuhan penduduk Desa Citaman dapat dilihat pada tabel di bawah ini :

\section{Tabel 4}

Laju Pertumbuhan Desa Citaman Tahun 2012 - 2014

\begin{tabular}{|c|c|c|c|c|}
\hline \multirow{2}{*}{ No. } & \multirow{2}{*}{ Rukun Tetangga } & \multicolumn{3}{|c|}{ Jumlah Penduduk (Jiwa) } \\
\cline { 2 - 5 } & & $\mathbf{2 0 1 2}$ & $\mathbf{2 0 1 3}$ & $\mathbf{2 0 1 4}$ \\
\hline 1 & RT 01 & 192 & 222 & 231 \\
\hline 2 & RT 02 & 155 & 185 & 200 \\
\hline 3 & RT 03 & 161 & 201 & 213 \\
\hline 4 & RT 04 & 256 & 276 & 286 \\
\hline 5 & RT 05 & 195 & 235 & 250 \\
\hline 6 & RT 06 & 298 & 302 & 312 \\
\hline 7 & RT 07 & 273 & 293 & 304 \\
\hline 8 & RT 08 & 225 & 255 & 267 \\
\hline 9 & RT 09 & 206 & 239 & 250 \\
\hline 10 & RT 10 & 183 & 190 & 201 \\
\hline 11 & RT 11 & 167 & 171 & 183 \\
\hline 12 & RT 12 & 149 & 242 & 255 \\
\hline & Jumlah & $\mathbf{2 . 4 6 0}$ & $\mathbf{2 . 8 1 1}$ & $\mathbf{2 . 9 5 2}$ \\
\hline
\end{tabular}

Sumber : Data dari Ketua RT se-Desa Citaman

Berdasarkan hasil pengamatan di Desa Citaman Kecamatan Ciomas Kabupaten Serang Provinsi Banten Wilayah Desa Citaman adalah desa yang berbasis pertanian dan perkebunan, dan beberapa potensi ada Usaha Mikro dan Kecil diantaranya Emping, Tempe, dan Kerupuk. Dan saat ini di desa tersebut sangat diperlukan adanya pengembangan- 
pengembangan usaha yang tepat guna, mengingat dari sisi kesejahteraan di desa tersebut yang masih kurang.

Howkins (2001) dalam bukunya The Creative Economy menemukan kehadiran gelombang ekonomi kreatif setelah menyadari pertama kali pada tahun 1996 ekspor karya hak cipta Amerika Serikat mempunyai nilai penjualan sebesar US\$ 60,18 miliar yang jauh melampaui ekspor sektor lainnya seperti otomotif, pertanian, dan pesawat. Menurut Howkins ekonomi baru telah muncul seputar industri kreatif yang dikendalikan oleh hukum kekayaan intelektual seperti paten, hak cipta, merek, royalty dan desain. Ekonomi kreatif merupakan pengembangan konsep berdasarkan aset kreatif yang berpotensi meningkatkan pertumbuhan ekonomi. (Dos Santos, 2007).

\section{Strategi Mewujudkan Ekonomi Kreatif}

Untuk mengembangkan ekonomi kreatif, pemerintah Indonesia dibawah kepemimpinan presiden terpilih harus membuat beberapa strategi besar dan melaksanakan pembangunan secara terintegrasi antara masyarakat, swasta dan pemerintah. Beberapa strategi yang akan dilakukan sebagai berikut :

1. Menyiapkan insentif untuk memacu pertumbuhan industri kreatif berbasis budaya, mencakup perlindungan produk budaya, pajak, kemudahan memperoleh dana pengembangan, fasilitas pemasaran dan promosi, hingga pertumbuhan pasar domestik dan internasional.

2. Membuat roadmap industri kreatif yang melibatkan berbagai departemen dan kalangan termasuk swasta.

3. Membuat program komprehensif untuk menggerakkan industri kreatif melalui pendidikan, pengembangan SDM, desain, mutu dan pengembangan pasar.

4. Memberikan perlindungan hukum dan insentif bagi karya industri kreatif. Beberapa contoh produk industri kreatif yang dilindungi HKI-nya, di antaranya buku, tulisan, drama, tari, koreografi, karya seni rupa, lagu atau musik, dan arsitektur. Produk lainnya adalah paten 
terhadap suatu penemuan, merek produk atau jasa, desain industri, desain tata letak sirkuit terpadu dan rahasia dagang.

5. Pemerintah membentuk Indonesian Creative Council yang akan menjadi jembatan untuk menyediakan fasilitas bagi para pelaku industri kreatif. Keenam, pemerintah akan menyelenggarakan lomba Indonesia Creative Idol (ICI) 2008, yang bertujuan untuk melestarikan dan mengembangkan industri kreatif.

\section{METODE}

1. Identifikasi Masalah

Tim PPM Dosen mengidentifikasi masalah sesuai dengan rencana kegiatan, sebagai berikut ;

- Pengelolaan potensi alam yang belum optimal

- Kemampuan dan keterampilan usaha yang masih kurang

- Dukungan lembaga-lembaga terkait yang belum optimal

- Pendapatan masyarakat yang relatif masih kurang

2. Analisis Kebutuhan

Analisis ini meliputi ;

- Analisis kondisi masyarakat

- Pemetaan kondisi masyarakat

3. Penyusunan program

4. Pelaksanaan program

5. Pelatihan Promosi dan Publikasi

6. Evaluasi program

7. Monitoring

8. Pembuatan laporan

9. Jadwal Kegiatan, yaitu dari tanggal 18 Januari sd 11 Maret 2017

10. Rancangan Biaya

\section{HASIL DAN PEMBAHASAN}




\section{Deskripsi Pelaksanaan Kegiatan Per-Bidang Kegiatan}

- Secara umum hasil kegiatan PPM Dosen merupakan upaya pemecahan masalah dan pemenuhan akan kebutuhan masyarakat serta tercapainya tujuan sebagai indikator keberhasilan. Hasil pelaksanaan program kerja PPM dapat dirasakan dari beberapa indikator yang muncul atau adanya perbedaan pada masyarakat sebelum dan sesudah pelaksanaan di Desa Citaman Kecamatan Ciomas Kabupaten Serang Tahun 2017. Adapun rencana-rencana kegiatan yang berhasil direalisasikan dalam kegiatan PPM di Desa Citaman Kecamatan Ciomas Kabupaten Serang adalah sebagai berikut :

\section{Bidang Ekonomi}

1. Mengadakan penyuluhan dan membantu meningkatkan pendapatan pengusaha tempe kampung Cibarugbug Desa Citaman.

2. Membantu pengusaha tempe dalam proses produksi tempe kampung Cibarug Desa Citaman.

3. Membantu pengusaha kerupuk dalam proses produksi emping dan ceplis Desa Citaman.

4. Membantu pengusaha emping dalam proses produksi kerupuk Desa Citaman.

5. Memberikan penyuluhan mengenai pembuatan brownies pisang kepada ibu-ibu warga kampung Gunung Sumbul Desa Citaman yang dihadiri oleh ibu-ibu warga Kp. Gunung Sumbul.

* Bidang Keagamaan

1. Menghadiri pengajian bulanana di masjid kampung Gunung Sumbul Desa Citaman, membantu acara dan konsumsi.

2. Memberikan bimbingan tata cara sholat dan mengajar mengaji anak-anak warga Kp. Gunung Sumbul Desa Citaman yang dilaksanakan pada sore atau malam hari setelah waktu maghrib.

Bidang Sosial dan Budaya

1. Membantu petugas kebersihan dalam melakukan pemotongan rumput lapangan sepak 
bola sekaligus memberkan sosialisasi olahraga sepak bola.

2. Silaturrahmi ke rumah salah satu sesepuh yang merupakan pengrajin Golok Ciomas dan melakukan sesi Tanya jawab seputar sejarah desa Citaman Ciomas, dan Golok Ciomas.

3. Mengikuti kerja bakti bersama warga desa untuk membuat drainase

* Bidang Pemerintahan Desa

1. Mengikuti acara MUSREMBANGDES (Musyawarah Rencana Pembangunan Desa) di kantor desa / balai desa.

2. Merapikan arsip dan berkas di kantor desa Citaman.

3. Membantu staff kantor desa dalam surat menyurat.

4. Membantu mendistribusikan surat undangan sosialisasi untuk seluruh warga Desa Citaman.

5. Berpartisipasi dalam kegiatan Desa, "Program Keluarga Harapan".

6. Membuat dan memasang papan plang nama disetiap kampung di desa Citaman.

* Bidang Pendidikan dan Kesehatan

1. Kunjungan ke sekolah (SD, SMP), melakukan kunjungan-kunjungan ke sekolah dasar dan sekeolah menengah pertama untuk mengetahui pola belajar anak di sekolah.

2. Melakukan sosialisasi pendidikan di SMA 1 Ciomas.

3. Membantu kegiatan KBM di sekolah, membantu mengisi kegiatan belajar mengajar yang kosong dikarenakan guru yang tidak bisa hadir untuk mengajar.

4. Membantu belajar tambahan (les private dan bimbingan belajar), membantu anakanak dalam belajar di luar sekolah di karenakan dengan mengadakan lest privat untuk menambah wawasan pengetahuan anak-anak yang tidak di berikan di sekolah.

5. Kegiatan diskusi dengan kepala sekolah, guru dan komite sekolah, mengadakan kegiatan diskusi dengan kepala sekolah dan komite sekolah untuk mengetahui pola belajar anak yang baik dan efektif.

6. Membantu anak-anak desa dengan memberikan edukasi bahasa inggris dan teknologi 
terkini, memberikan edukasi bahasa inggris dan teknologi dikarenakan masih kurang nya edukasi yang di berikan sekolah terutama bahasa inggris dan teknologi, karena di jaman sekarang bahasa inggris dan teknologi merupakan edukasi yang penting bagi masa depan mereka.

7. Mengadakan kegiatan rutin belajar 2 kali dalam 1 hari bagi anak-anak desa yang belum bersekolah, mengadakan kegiatan rutin belajar 2 kali dalam sehari yaitu sesudah solat dzuhur (12:30) dan sesudah solat maghrib (18:30).

8. Mengikuti kegiatan posyandu Desa Citaman.

9. Mengadakan senam sehat.

10. Mengadakan sosialisasi dan praktik sikat gigi sehat.

11. Mengajak warga Desa Citaman untuk melakukan operasi semut di lingkungan sekitar Kp. Gunung Sumbul.

12. Menyelenggarakan penyuluhan narkoba bersama dengan mahasiswa KKM Mandiri Untirta.

\section{Evaluasi dan Harapan Masyarakat (Stakeholders)}

Adanya kegiatan PPM tentunya memberikan kesan dan harapan tersendiri bagi masyarakat. Maka evaluasi kegiatan dan harapan dari masyarakat bedasarkan bidang-bidang kegiatan, antara lain ;

\section{Bidang Ekonomi}

Para pelaku Usaha Mikro dan Kecil yang dikunjungi merasa terbantu dengan adanya kegiatan PPM ini, baik dari aspek produksi hingga dengan aspek pemasarannya. Harapan dari pelaku Usaha Mikro dan Kecil Desa Citaman yaitu adanya koperasi peminjaman modal untuk warga Desa Citaman agar mudah dalam memperoleh modal untuk usaha.

2. Bidang Keagamaan

Masyarakat KP. Gunung sumbul menyambut dengan baik ketika mengikuti pengajian bulanan "Manakim" di masjid.

Beberapa warga masyarakat Kp. Gunung Sumbul sangat antusias dengan kegiatan- 
kegiatan yang menjadi program kerja PPM.

3. Bidang Sosial dan Budaya

Begitu banyak kegiatan sosial dan budaya di Desa Citaman yang bisa diikuti dan dipelajari. Namun keterbatasan waktu ternyata tidak memungkinkan untuk mendalami semuanya.

4. Bidang Pemerintahan Desa

Bidang pemerintahan desa merupakan bidang yang tidak kalah penting dengan bidang yang lainnya, yang mana program-program yang disusun dimaksudnkan untuk membantu aparat desa dalam melaksanakan tugas yang adadi kantor desa maupun di lingkungan masyarakat Desa Citaman.

5. Bidang Pendidikan dan Kesehatan

Pendidikan dan kesehatan merupakan hal yang sangat penting dimiliki oleh masyarakat Desa Citaman. Dengan adanya PPM yang mengadakan kegiatan mengajar bahasa Inggris, les atau pelajaran tambahan, sosialisasi kesehatan, dan senam ini warga lebih terbantu dalam meningkatkan pengetahuan kepada anak-anak juga mengetahui pentingnya menyikat gigi dan berolahraga untuk kesehatan manusia. Masyarakatberharap untuk selanjutnya akan ada program atau kegiatan yang dapat memberikan kontribusi dalam meningkatkan pengetahuan masyarakat.

\section{KESIMPULAN}

Pelaksanaan pendampingan dan pengembangan masyarakat merupakan salah satu tujuan dari kegiatan PPM yang diharapkan mampu untuk dapat menyelesaikan permasalahan yang ada di masyarakat Desa Citaman, baik di bidang perekonomian, keagamaan, sosial dan budaya, pemerintahan desa, maupun di bidang pendidikan dan kesehatan. Melalui pendampingan terhadap masyarakat, kegiatan PPM Dosen ini melakukan penggalian data tentang persoalan atau kondisi masyarakat sekitar yang selanjutnya dirumuskan dalam bentuk program kerja dan realisasinya yang diharapkan dapat menjawab persoalan yang ada bersama dengan masyarakat. Kemudian program kerja yang dirumuskan telah terealisasi kurang lebih 90\% sesuai dengan kemampuan peserta PPM, meskipun masih terdapat kendala dalam pelaksanaannya. 


\section{DAFTAR PUSTAKA}

Capello, Roberta, (2007), Regional Economics, Routledge, New York.

Direktorat Riset dan Pengabdian Kepada Masyarakat, (2017), Panduan Pelaksanaan dan Pengabdian Kepada Masyarakat di Perguruan Tinggi, Edisi XI

Djumena, Erlangga (2011), Ekonomi Fiskal \& Moneter Saham \& Valas Analisis Sosok Inspirasi Perencanaan Keuangan, http://bisniskeuangan.kompas.com., akses tgl 5 Juni 2012

Gibb, A.A. (1987), "Enterprise culture - its meaning and implication for education and training", Journal of European Industrial Training, Vol 11, No. 2, pp. 1-38.

Kusuma, Jaka Wijaya; Jefri, Ulfi; Surnani, Endang; Pratiwi, Ika; Kurniawan, E. (2020). PELATIHAN PENGGUNAAN APLIKASI CLASSDOJO SEBAGAI UPAYA PENINGKATAN PEMBELAJARAN JARAK JAUH BAGI GURU SD IT BINA BANGSA DI ERA KENORMALAN BARU. JPKM-Aphelion (Jurnal Pengabdian Kepada MasyarakatAphelion), 1(01), 57-67. http://openjournal.unpam.ac.id/index.php/JPKA/article/view/6906

STIE Bina Bangsa, (2017), Panduan Pengabdian Kepada Masyarakat (P2M) Bagi Dosen, Bina

Kreasindo, Serang

Suhodo, Diah Setiari (2010), Industri Kreatif, Solusi Baru Ekonomi Indonesia, http://www.ekonomi.lipi.go.id/informasi/buletin/journal, akses 7 Juni 2012

Tavris, C (1992), The Mismeasure of Women, Simon and Schuster: New York, NY.

Zaini, Afrizal Woyla Saputra (2011), Rendahnya Daya Saing Indonesia Terhadap Negara-Negara Maju, Paper, 28 Mei 2011 